\title{
SOBREEDUCACION EN EL MERCADO LABORAL CHILENO
}

OVEREDUCATION IN THE CHILEAN LABOR MARKET

\section{DANIEL J. CASTRO RAMIREZ*}

Universidad Alberto Hurtado

\begin{abstract}
The research investigates the impact of over-education in the Chilean workforce, using data from the PIAAC and CASEN surveys from 2003 to 2015. The results show that on average $37 \%$ of workers with higher education are classified as "over-educated" in the period 2003-2015. In addition, the majority of this "over-educated people" come from private universities and perform in technical, administrative and legislative jobs. I also use the 2015 CASEN survey to analyze the probability of being over-educated. The results show that workers with a technical or non-traditional degree in professional education institutes and private universities are those who are more likely to be considered "over-educated". Moreover, I implemented a propensity score matching methodology using the CASEN survey 2015 to study the impact of over-education on wages and on-the-job training. The results suggest a negative impact of over-education on wages.
\end{abstract}

Keywords: Overeducation, mismatch, Propensity Score Matching.

JEL Classification: $J 22, J 24$.

* Master of Arts in Economics de Georgetown University y Magíster en Economía de la Universidad Alberto Hurtado. E-mail: castrocrossfit@gmail.com

Las opiniones expresadas en este documento y los errores subsistentes son de exclusiva responsabilidad del autor. El autor agradece los valiosos comentarios de Lucas Navarro y Mauricio Tejada. 


\section{Resumen}

En esta investigación se aborda la incidencia de la sobreeducación en la fuerza laboral empleada chilena. Los resultados muestran que los trabajadores con estudios superiores catalogados como sobreeducados alcanzan en promedio el $37 \%$ del total de trabajadores ocupados con educación superior, en el período 2003-2015. Utilizando la metodología de evaluación de impacto Propensity Score Matching se estima el impacto en la brecha salarial y en la proporción de capacitados (trabajadores que han realizado capacitaciones laborales) entre los trabajadores sobreeducados en relación con los no sobreeducados. Se encuentra evidencia que los sobreeducados perciben menor sueldo.

Palabras clave: Sobreeducación, desajuste, Propensity Score Matching.

Clasificación: JEL: J22, J24.

\section{INTRODUCCION}

En el mercado laboral comúnmente se encuentran empleadores que buscan trabajadores y a su vez trabajadores que buscan empleos ofrecidos por estos empleadores. Dicho mecanismo de búsqueda por ambas partes asigna empleos a trabajadores que por sus elecciones y atributos aceptan dichos empleos y, por otro lado, empleadores que por sus necesidades productivas contratan a trabajadores para dichos empleos. Dicho mecanismo no nos asegura que tanto para el trabajador como para el empleador la elección sea la más apropiada. Dicho en otras palabras, existen empleos que podrían ser mejor elección para el trabajador o deben existir trabajadores que por sus cualidades son más idóneos para dicho empleo. Es en esta idea donde nace el concepto de sobreeducación, el que se define como trabajador que, por sus estudios, está excesivamente educado para la labor que desempeña o, de igual manera, la labor que desempeña requiere conocimientos inferiores a los alcanzados por el trabajador.

El concepto de sobreeducación cobra relevancia para la ciencia económica, ya que, por un lado, las empresas al no poder ajustar sus métodos productivos y así no poder aprovechar en su totalidad la productividad del trabajo a su disposición, estarán produciendo bajo su capacidad potencial y, de persistir este fenómeno a largo plazo, la economía no estará produciendo en su máxima capacidad (PIB potencial). Por otro lado, la sobreeducación es en especial perjudicial para los trabajadores, ya que la formación de capital humano es costosa para el trabajador, tanto en tiempo como en dinero. Brynin (2002), Korpi y Táhlin (2009) consideran que la sobreeducación se asocia a sanciones salariales, malas expectativas laborales y estrés psicológico. Además, Ortiz (2010), Tsang y Levin (1985) asocian la sobreeducación a una menor productividad. 
Por último, está uno de los aspectos más importantes para esta investigación: la importancia que tiene la sobreeducación también en las políticas educacionales. En Chile se han impulsado políticas como el crédito con aval del Estado (CAE), crédito CORFO a la educación superior y gratuidad en los estudios de educación superior para el $60 \%$ de los estudiantes más vulnerables. Dichas políticas tienen por objetivo aumentar el acceso a la educación superior. Como se observa en la Figura 1, el aumento en el porcentaje de la fuerza laboral con estudios superiores ha ascendido en más de diez puntos porcentuales en los últimos doce años, producto de dichas políticas. Este incremento supone entonces un aumento en el número de familias que deben invertir en gastos de educación superior. A su vez, aumenta el gasto para el Estado, ya que debe financiar las políticas de subvención para la educación superior. Es en este punto donde el concepto de sobreeducación cobra una real dimensión, porque es lícito cuestionar cuál es y ha sido la reacción de la demanda laboral frente a este aumento en la oferta laboral con estudios superiores y si ha sido capaz de aprovechar dicho aumento. Duncan y Hoffman (1981) advierten que la sobreeducación reflejaría una mala asignación de los recursos laborales. Dicho de otra manera, la demanda laboral no está aprovechando la total capacidad de la oferta laboral a su disposición por presencia de sobreeducación.

\section{FIGURA 1}

GRAFICO DE COMPOSICION EDUCACIONAL SUPERIOR DE LA FUERZA LABORAL

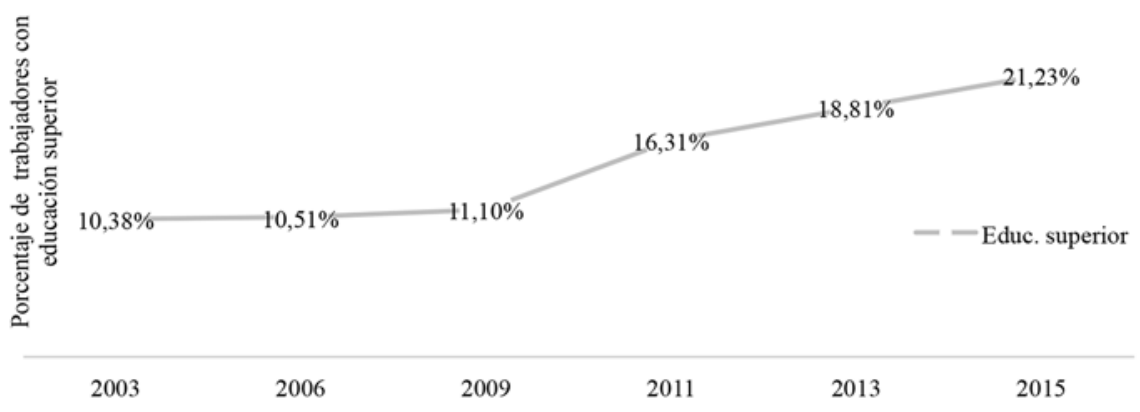

* Fuente: CASEN 2003-2015.

Teniendo estas premisas, es interesante mencionar las problemáticas que se abordarán en esta investigación. Una de ellas es cuantificar cuál ha sido la incidencia de la sobreeducación en la fuerza laboral empleada en Chile. Para ello se pretende medir la incidencia en porcentaje de la sobreeducación utilizando la encuesta PIAAC para 
Chile, de la que obtendremos los requerimientos educacionales para cada ocupación, es decir, la educación o título profesional necesario para desempeñar dicha labor. Los resultados son extrapolados a las encuestas CASEN 2003 al 2015, para así poder contrastar la educación obtenida por el trabajador y la educación requerida para la labor que desempeña, y con ello obtener el porcentaje de sobreeducados por tipo de universidad (pertenecientes o no al CRUCH), tipo de ocupación y por edad entre los 21 a 55 años. De estos análisis se desprenderán los siguientes resultados: un mayor porcentaje de trabajadores sobreeducados que se titulan de universidades que no pertenecen al CRUCH; un mayor porcentaje de trabajadores sobreeducados que se desempeñan en labores de oficina, legislativas o técnicas; y un mejor porcentaje de trabajadores que pertenecen al tramo etario de 20 a 30 años y al tramo etario de 40 a 55 años. De la evidencia aportada del análisis anterior es que se plantea la segunda problemática a tratar, esta consiste en identificar qué factores inciden en la propensión a estar o no sobreeducado por medio de la edad. Para solucionar esa problemática es que se utilizará el modelo probabilístico PROBIT para poder capturar diferencias substanciales en los determinantes de estar o no sobreeducado (edad, sexo, universidad, ocupación, etc.), mediante tres tramos etarios (tramo de 20 a 30 años, de 30 a 40 años y de 40 a 50 años).

Finalmente, se proponen dos problemáticas a tratar. En primer lugar se plantea que los sobreeducados son en promedio menos remunerados, es decir, el empleo es el determinante del salario y no los estudios, por tanto el salario no dependería de la productividad potencial del trabajador. En segundo lugar se plantea que los trabajadores sobreeducados poseen menos capacitaciones laborales, por tanto, menos habilidades laborales. Entonces, para tratar dichas problemáticas es que se utiliza la metodología de Propensity Score Matching en sus siglas en inglés para testear diferencias salariales y la proporción de capacitaciones laborales consistentes que pudieran tener trabajadores sobreeducados versus trabajadores no sobreeducados.

Esta investigación se organiza en cuatro secciones. La primera sección titulada "Literatura Empírica y Teórica" recopilará la metodología, modelos teóricos y resultados empíricos y teóricos de los principales trabajos referentes a la sobreeducación.

En la segunda sección, titulada "Metodología y Dato", se detallarán las metodologías y los datos a usar en esta investigación.

En la tercera sección, titulada "Resultados", se expondrán los principales resultados obtenidos en esta investigación, los que corresponden a los porcentajes de trabajadores sobreeducados para Chile por tipo de universidad (CRUCH o privadas), por tramo etario (tramos de 20 a 30 años, de 30 a 40 años y de 40 a 50 años) y por tipo de ocupación u oficio. También se presentarán los principales resultados obtenidos del modelo PROBIT. Finalmente se expondrán los resultados referentes a las diferencias de los grupos de sobreeducados y no sobreeducados en ambos géneros para determinar la brecha salarial y proporción de capacitados entre sobreeducados y no sobreeducados, ambos grupos con estudios superiores.

Finalmente, en la última sección se presentarán las conclusiones de esta investigación. 


\section{LITERATURA EMPIRICA Y TEORICA}

En la siguiente sección se abordará la literatura empírica y teórica referente a la sobreeducación que compete a esta investigación, teniendo como evidencia estudios previos.

\subsection{Literatura empírica}

La literatura empírica referente a la sobreeducación plantea dos problemas. El primer problema es cómo medir los requerimientos educacionales de las ocupaciones y oficios. Para ello se ahondará en la metodología de evaluaciones subjetivas de los requerimientos educacionales. El segundo problema es cómo comparar la educación obtenida por el trabajador y el requerimiento educacional de la labor que desempeña este. A continuación se detalla la literatura referente a estos dos problemas.

\subsubsection{Mediciones subjetivas del requerimiento educacional para cada ocupación}

Según Hartog (2000), Sloane (2003), McGuinness (2006) y Groot y Maassen Van den Brink (2000a), la literatura ofrece medidas subjetivas para la medición de los requerimientos educaciones para cada ocupación.

Las medidas subjetivas de los requerimientos educaciones para cada ocupación se realizan mediante la información proporcionada por encuestas hechas a trabajadores como cuando al entrevistado se le pregunta por el nivel mínimo requerido para postular a su puesto (autoevaluación indirecta) o directamente se le pregunta si está sobreeducado o no (autoevaluación directa). Algunos ejemplos de medición subjetiva de la sobreeducación son los siguientes: Sicherman (1991) utiliza respuestas a la pregunta “ ¿Cuánta educación formal se requiere para conseguir un trabajo como el tuyo?", Alba-Ramírez (1993) utiliza la pregunta “¿Qué tipo de educación necesita una persona para realizar su trabajo?" y Galasi (2008) mide los requerimientos al trabajo por medio de la pregunta "Si alguien está aplicando hoy en día para el trabajo que haces ahora, ¿necesitarían alguna educación o educación vocacional más allá de la educación obligatoria? Y si es así, ¿cuántos años de educación o de educación profesional más allá de la educación obligatoria necesitarían?’. Es importante mencionar que Alba-Ramírez (1993) hace referencia a las habilidades o el contenido cognitivo de una labor, con ello trata de capturar habilidades informales y no la educación formal o parámetros de contratación.

Sin embargo, las medidas subjetivas de los requerimientos educacionales para cada ocupación han sido fuente de críticas. Sloane (2003) y Flisi et al. (2017) afirman que las personas excesivamente educadas son propensas a no contestar o a inflar la educación necesaria para elevar sus estatus, con lo que se podría estar sobreestimando la sobreeducación. Además, McGuinness (2006) advierte que hay problemas asociados con este tipo de medidas, ya que trabajadores pertenecientes a organizaciones 
pequeñas o mal estructuradas suelen tener una mala o vaga comparativa respecto de requerimientos educaciones de sus puestos de trabajos. Además, los criterios con los que los trabajadores reportan los requerimientos educacionales pueden diferir, con ello se generará una amplia gama de respuestas, ocasionando un problema. También Dumont y Monso (2007) siguieren que estas medidas pueden tener sesgos debido a cómo se formula la pregunta y los autores sostienen que este tipo de medidas pueden ser afectadas por variables externas específicas de cada país. Por otro lado, Cattani et al. (2014) advierten que estas medidas pueden verse afectadas por las satisfacciones laborales, como las recompensas económicas por los títulos obtenidos. Además, los autores sostienen también que los trabajadores pueden percibir su trabajo como inadecuado para su nivel educativo, de hecho, podrían basar sus respuestas en malas recompensas salariales, incluso si el contenido cognitivo de las labores asignadas es acorde al nivel educativo, alterando así estas medidas.

No obstante, Green et al. (1999), utilizando una base de datos de antiguos alumnos de la Universidad de New Castle, Reino Unido, encuentran que hay bastantes similitudes entre el nivel educacional necesario para desempeñar un trabajo y el requerimiento educacional necesario para postular a este, lo que sugiere una consistencia en el enfoque subjetivo de la medición de la sobreeducación. Además, Van der Velden y Van Smoorenburg (1997) favorecen medidas subjetivas de los requerimientos educaciones para cada ocupación por sobre otro tipo de medidas, ya que estas no sobrestiman sistemáticamente el nivel de sobreeducación. También, McGuinness (2006), Groot y Van den Brink (2000b) postulan que, si bien estas medidas tienden a superar a otro tipo de medidas, ellas tienden a dar conclusiones consistentes.

\subsubsection{Comparación de los requerimientos educacionales y la educación obtenida}

Sala (2011) define como "coincidencias realizadas" a la equidad de la educación efectiva y terminada con los requerimientos educacionales del empleo que se realiza. Además, el autor sostiene que habrá desajuste en "coincidencias realizadas" cuando la educación del trabajador es una desviación mayor o menor al promedio del requerimiento educacional de la labor que desempeña dicho trabajador. Farooq (2016), Mendes de Oliveira et al. (2000) y Verdugo (1989) proponen comparar la moda de los requerimientos para cada ocupación con la educación alcanzada por el trabajador. Sin embargo, estos autores señalan que este método no está exento de problemas como, por ejemplo, cuando se asume que todos los empleos dentro de una misma ocupación poseen los mismos requerimientos o los reportes de los requerimientos pueden pertenecer a tiempos muy dispares, con lo que habría efectos de cohorte.

Groeneveld y Hartog (2004) advierten que en la medida que los reportes de los requerimientos educacionales para cada labor reflejen los estándares de contratación de las empresas, estos no logran descubrir los requisitos educacionales y tecnológicos de una labor. Además, Leuven y Oosterbeek (2011) precisan que los requerimientos 
educacionales miden la real asignación de habilidades a cada labor. Dicha asignación es determinada por las normas de contratación y las condiciones del mercado laboral. Sin embargo, los autores advierten que dicha asignación es endógena, por tanto, los requerimientos educacionales deben interpretarse como el resultado o equilibrio en un mercado de trabajo y no un parámetro de cambio de demanda.

\subsection{Evidencia empírica}

Los principales aportes se pueden observar en la Tabla 1, donde se detalla la incidencia de la sobreeducación como porcentaje de la fuerza laboral activa.

\section{TABLA 1}

TABLA DE INCIDENCIA DE SOBREEDUCADOS EN LA FUERZA LABORAL ACTIVA

\begin{tabular}{|l|l|l|c|c|}
\hline \multicolumn{1}{|c|}{ Autor } & Año & \multicolumn{1}{c|}{ País } & Data & Incidencia (\%) \\
\hline Dolton et al. & 2000 & UK & 1986 & 30 \\
Chevalier, A. & 2003 & UK & 1996 & 17 \\
Sloane et al. & 1999 & UK & $1986-1987$ & 30,63 \\
Daly t al. & 2000 & US & 19761976 & 37,65 \\
Duncan y Hoffman & 1981 & US & 1976 & 42 \\
Sicherman & 1981 & US & 1976 y 1978 & 40,8 \\
Verdugo y Verdugo & 1989 & US & 1980 & 10,9 \\
Buchel et al. & 2002 & US & 1998 & 15,8 \\
McGuinness & 2003 & Irlanda del Norte & 1999 & 24 \\
Green et al. & 2016 & Austria & 2013 & 28,6 \\
Green et al. & 2016 & Irlanda & 2013 & 37,1 \\
Green et al. & 2016 & Japón & 2013 & 48,5 \\
Green et al. & 2016 & Canadá & 2013 & 37,2 \\
Green et al. & 2016 & R. Checa & 2013 & 37,3 \\
Leuven y Oosterbeek & 2011 & América Latina & - & 24 \\
\hline
\end{tabular}

* Elaboración propia.

\subsection{Literatura teórica}

La literatura teórica ofrece tres grandes modelos en los que se sitúa el concepto de sobreeducación: Teoría del Capital Humano, Modelo de Competencia de Empleos y Modelo de Asignación de Empleo. Sloane (2003) estipula que el aporte principal de esta literatura y, por tanto, de los tres modelos ya mencionados, es ampliar el debate acerca de la importancia de las características del empleo como determinante de salario. 


\subsubsection{Teoría del Capital Humano (TCH)}

El Capital Humano de Becker (1964), Heckman et al. (2003) y el modelo de ingresos de Mincer (1974) nos aportan el marco teórico fundamental y empírico en donde se desarrollan y miden las principales predicciones de los modelos de TCH. En cuanto a este tipo de modelos, los autores sostienen que las empresas ajustan sus mecanismos productivos frente al cambio en la oferta relativa de la mano de obra con el fin de utilizar plenamente las capacidades de la mano de obra disponible. Además, Becker (1964) postula que, en este tipo de modelos, al trabajo se le pagará siempre su productividad marginal, por tanto, los salarios son el reflejo de sus productividades marginales individuales, las que serán determinadas por la acumulación de capital humano (estudios). Sin embargo, McGuinness (2006) advierte que la sobreeducación está relacionada con la subutilización de capital humano y, por este motivo, con salarios que están por debajo de la productividad marginal, por tanto esta sería incompatible con este tipo de modelos, ya que la educación o acumulación de capital humano como señalización de productividad no funciona.

McGuinness (2006) plantea que la sobreeducación, vista como un fenómeno a corto plazo y provocada por la tardía de los ajustes en los mecanismos de producción de las firmas para utilizar plenamente su capacidad laboral, es completamente plausible en el enfoque de los modelos TCH. Caso contrario: si la sobreeducación es un fenómeno a largo plazo, esta sería completamente incompatible con este tipo de modelos.

En el marco empírico, McGuinness (2006) postula que la comprobación empírica para la TCH puede aportar una explicación completamente coherente con la visión neoclásica. El modelo es desarrollado por Mincer (1974) basado en una regresión que explica los retornos monetarios de los años de educación. Entonces, la sobreeducación observada como menores pagos a trabajadores más educados sería explicada por una o más variables omitidas, la clave se centra en medidas de educación menos formales como las capacitaciones laborales no observadas. Además, Becker (1964) sostiene que estas son sustitutos a los medios de educación más formales, de modo que se observarían individuos con menor educación formal que compensarían la falta de esta por educación menos formal. Por otro lado, McGuinness (2006) sostiene que si se observan individuos con más años de educación y menores salarios es debido a un fenómeno de variable omitida, en tanto no se controle por medidas de educación menos formales.

Por último, McGuinness (2006) considera que las medidas de habilidades o capacidades productivas pueden explicar diferencias salariales entre individuos homólogamente educados, en tanto los individuos con menores habilidades recibirían salarios menores. Por ello, el autor advierte que si los modelos empíricos no son capaces de controlarse por dichas habilidades, se generaría un sesgo en la estimación de los efectos salariales para los trabajadores sobreeducados.

En conclusión, la sobreeducación siguiere que la TCH es incompatible con los datos observados, en la medida que esta persista en controles como los de las habilidades 
productivas y medidas de educación menos formales. Otro aspecto a tener en cuenta es que la sobreeducación será incompatible con los modelos TCH si esta es un fenómeno a largo plazo.

\subsubsection{Modelo de competencia laboral}

Duncan y Hoffman (1981), y Hartog y Oosterbeek (1988) sostienen que las empresas no logran ajustar sus técnicas de producción frente a variaciones en el costo de los factores, en especial si las empresas cuentan con tecnología orientada al trabajo en equipo o agrupan trabajos heterogéneos. Además, los autores consideran que pueden existir rigideces en el costo de los factores, como en el salario (acuerdos colectivos, contratos anules, etc.), con esto los factores productivos no se ajustarían al cien por ciento como lo sugiere la TCH. Además, los autores concluyen que si las empresas no pueden adaptarse a cambios en los precios de los factores, los salarios y la productividad quedarán determinados por el empleo. En esta misma línea, Thurow (1975) surgiere que en el modelo de competencia laboral el tipo de empleo es el único factor determinante en la productividad y salario del individuo, de manera que el salario y la productividad no necesariamente deben coincidir.

En el modelo de Thurow (1975), el autor indica que los individuos compiten por puestos de trabajos basándose en los costos relativos de capacitación. El concepto central en las observaciones de Thurow (se cita de las encuestas de EE.UU.) es que la mayoría de las habilidades necesarias para un trabajo se aprenden en este, en consecuencia, el mercado de trabajo es más similar a la visión de mercado de formación de habilidades que a una visión de mercado de oferta y demanda de habilidades, donde dichas formaciones se deben asignar a determinados trabajadores. Además, McGuinness (2006) sostiene que la manera de asignar las formaciones de empleos es mediante factores que ordenan (generan una cola) a los trabajadores y a la distribución de puestos de trabajos (oportunidades de formación) disponibles en una economía. Una vez asignada la "oportunidad de formación" a un trabajador, su productividad y su salario quedarán determinados por las características del empleo en cuestión y, más importante aún, la productividad no quedará determinada por las habilidades del trabajador.

\subsubsection{Modelos de asignación}

McGuinness (2006) postula que, en este tipo de modelos, la característica principal es que todos los trabajos, las diferencias pertinentes entre trabajadores, las tecnologías que relacionan a los trabajadores con la producción y los mecanismos que asignan a los trabajadores al empleo están a disposición de los trabajadores.

McGuinness (2006) también sostiene que, a diferencia de los modelos de competencia laboral, la elección de empleos no es meramente determinada por factores 
económicos o por las características del individuo, es decir, hay un paso intermedio entre las características de un individuo y su salario. Dicho paso intermedio hace referencia a trabajadores que observan empleos y eligen lo que maximiza su utilidad o ganancias. En consecuencia, la elección de empleo que maximiza dicha utilidad asigna trabajadores a determinados puestos. Además, McGuinness (2006) sostiene que la principal contribución de este tipo de modelos es que la distribución salarial tiene que tener en cuenta no solo las características del empleo, sino también las del individuo. En consecuencia, la sobreeducación es coherente en este tipo de modelos, ya que los salarios y la productividad no irán de la mano, los estudios u otros atributos individuales no estarán totalmente relacionados con la productividad (modelos de capital humano) y las tasas salariales no se relacionarán del todo con las características del empleo (modelo de competencia de empleo).

\subsection{Evidencia teórica}

McGuinness (2006) sostiene que la mayoría de la evidencia empírica emanada de ecuaciones para calcular los beneficios de los años de educación sugiere que los rendimientos a la educación de los años que exceden los años requeridos por un empleo son positivos y significativos, pero tienden a ser inferiores a los beneficios de los años de educación requeridos. Esta evidencia es considerada en contra de los modelos de capital humano. Sin embargo, Rumberger (1987) no encontró beneficios adicionales a los años excedentes de escolaridad en ciertas ocupaciones, lo que siguiere que quizás los modelos de competencia laboral pueden explicar mejor los comportamientos dentro de una ocupación en particular.

Hartog y Oosterbeek (1988) concluyen que la participación y las horas trabajadas para la oferta laboral femenina en Holanda poseen elasticidades sustancialmente más altas que la de los hombres. Esto explicaría por qué a las mujeres se les pagaría el rendimiento escolar real inclusive en empleos en donde se reporte sobreeducación. Los autores también sugieren que las elasticidades de oferta femenina son decrecientes con el nivel educativo, lo que permite que exista una corrección total entre salarios, inclusive para puestos de trabajo donde la mujer no tiene educación. Además, Vahey (2000) no reportó menores retornos a los años de sobreeducación para mujeres canadienses, pero sí observó menores retornos para años de sobreeducación en hombres canadienses.

Battu y Sloane (2000) examinaron las predicciones de la TCH, las que expresan que las empresas mejoran las tareas de los empleados sobreeducados, probando así la hipótesis de que la sobreeducación es un fenómeno de corto plazo. Los autores no encuentran evidencia de que los trabajadores sobreeducados convergen a labores acordes a su nivel educacional, lo que surgiere que la sobreeducación puede ser un fenómeno de largo plazo. Por último, McGuinness (2003a) rechaza la hipótesis de que los coeficientes de capital humano y las variables que describen el empleo son cero conjuntamente en un modelo de ecuación salarial, lo cual refutaría las conclusiones 
del modelo de asignación respecto de la asignación de capital humano y características del empleo como determinantes del salario y de la productividad.

Groot (1996) encontró evidencia de que los trabajadores más jóvenes y de mayor educación trabajan relativamente en menos puestos de trabajo que requieran sus estudios versus los trabajadores de mayor edad. Los autores sostienen que este fenómeno de sobreeducación en los más jóvenes puede ser debido a que los trabajadores más experimentados entraron al mercado laboral cuando había una mayor cantidad de bacantes por empleos de alta calificación, evidenciando un efecto cohorte etario y no de edad. Idea similar sostiene Farooq (2016), quien sugiere que la alta sobreeducación en jóvenes es debido a la falta de habilidades adquiridas por la experiencia, además, que los trabajadores próximos a la edad de jubilación también presentarían una mayor sobreeducación, debido a la desvalorización de dichas habilidades.

Groot (1996) examina la premisa de que los trabajadores sobreeducados son menos capaces que sus pares bien emparejados, reportando que los efectos negativos de los salarios en hombres sobreeducados aumentan con el tiempo. Esto apoya la hipótesis de que los empleadores pagan menos al descubrir las menores habilidades de los trabajadores sobreeducados. En esta misma línea, Sloane et al. (1999) sugieren que los trabajadores sobreeducados son menos productivos.

Dolado et al. (2009) postulan para España que lo esencial para explicar la sobreeducación es la movilidad de empleo a empleo (on-the-job). Los autores sostienen que los buscadores de empleo estarían dispuestos a aceptar ofertas laborales que requieran menos habilidades que las ya obtenidas, si una vez empleados existen expectativas de poder encontrar un mejor trabajo. Además, Alba-Ramírez (1993) postula ideas similares, pero atribuye además que los trabajadores buscarían experiencia laboral, con el fin de mejorar sus habilidades laborales, y así poder optar a mejores empleos.

\section{DATOS Y METODOLOGIAS}

A continuación se detallarán los datos a usar y la metodología.

\subsection{Datos}

En esta sección se detallan los datos a usar, las encuestas de dónde provienen y cómo fueron tratados estos datos.

La encuesta de evaluación de competencia para adultos PIAAC para Chile es realizada por la OCDE para los países miembros. Esta encuesta fue realizada desde el 1 de agosto del 2011 hasta el 31 de marzo del 2012 a individuos que van de los 16 a los 65 años de edad, la que consta de 2.559 observaciones, de estas 1.269 observaciones son hombres y 1.290 son mujeres. Además, en esta encuesta se caracteriza el nivel educacional y título necesario para desempeñar las labores que van de sin educación hasta doctorado. 
La encuesta de Caracterización Socioeconómica Nacional (CASEN) año 2015 es una encuesta que busca representar la condición socioeconómica de los hogares chilenos. Para esta encuesta se utilizará una muestra de 14.678 observaciones, estas corresponden a trabajadores asalariados dependientes. Del total de dicha muestra, 93,9\% posee contrato de trabajo escrito, $32,74 \%$ es empleado u obrero del sector público, $67,26 \%$ es empleado u obrero del sector privado, $88,32 \%$ es trabajador permanente, $6,19 \%$ es trabajador a plazo o a tiempo determinado, $2,99 \%$ es trabajador de temporada o estacional, $44,73 \%$ es trabajador hombre y $55,27 \%$ es trabajador mujer. También, del total de trabajadores con contrato de trabajo escrito, $85,59 \%$ es a jornada completa y $8,9 \%$ es a jornada parcial, $4,06 \%$ es a jornada prolongada, $74,9 \%$ posee un contrato indefinido y $25,10 \%$ posee un contrato a plazo fijo. Además, en esta encuesta solo se consideraron observaciones que reportaran la edad del individuo (entre 20 y 50 años), educación superior (educación técnica, universitaria o postgrado), sexo (masculino o femenino), sindicalización (pertenece o no a un sindicato), nacionalidad (nacional o extranjera), salario, región de residencia, tipo de empresa en la que trabaja (empresa pública o privada) y en qué tipo de institución realizó los estudios superiores (CFT, instituto profesional, universidades privada o perteneciente al CRUCH). Finalmente se utilizarán las encuestas CASEN desde el 2003 hasta el 2015 con el fin de poder cuantificar la evolución del porcentaje de sobreeducados en dicho período.

\subsection{Metodología}

En esta sección se explicará la metodología a usar, la que se organiza en tres objetivos: medir el requerimiento educacional para cada ocupación, medir el porcentaje de trabajadores sobreeducados, y obtener diferencias consistentes en salarios y capacitaciones entre sobreeducados y no sobreeducados. Para esto último se plantea el método de Propensity Score Matching (PSM).

\subsubsection{Los requerimientos educacionales para las diversas ocupaciones}

De la encuesta PIAAC para Chile se obtendrá una aproximación a los requerimientos educacionales para cada ocupación por medio de la pregunta "Todavía estamos hablando sobre su trabajo actual, si estuviera postulando hoy, ¿cuál sería el nivel educacional que alguien necesitaría para obtener este tipo de trabajo?". En dicha pregunta, el encuestado responde el nivel educacional que cree necesario tener un postulante para poder obtener dicho trabajo. Para determinar un único requerimiento educacional, Farooq (2016) sugiere aplicar el siguiente criterio: obtener la moda para la distribución de respuestas para cada ocupación. Si esta moda es mayor o igual al $50 \%$ de las respuestas totales, se considerará como el requerimiento educacional para dicha ocupación. Si la moda no supera el 50\% del total de respuestas, se calcula la segunda mayoría de respuestas. Y si la moda supera en 5\% a la segunda mayoría, 
se considera como el requerimiento educacional (en caso contrario, se consideran ambas).

\subsubsection{La medición de la sobreeducación}

La información de los requerimientos educacionales para cada labor obtenidos de la encuesta PIAAC es extrapolada a la encuesta CASEN, dicho en otras palabras, para cada ocupación en la encuesta CASEN obtenemos el requerimiento educacional de la encuesta PIAAC para dichas ocupaciones. Esto fue posible, ya que ambas encuestas categorizan cada ocupación en grupos homólogos, lo que hace a las encuestas comparables entre sí. Estas categorías para ambas encuestas se presentan en la Tabla 2.

Finalmente, es necesario tener una definición formal de trabajador sobreeducado. Para ello se utilizará la definición aportada por Farooq (2016), la que representa al trabajador sobreeducado como aquel con estudios superiores y que desempeña labores en el trabajo que no requieren de dichos estudios.

\section{TABLA 2}

TABLA DE CATEGORIAS DE LAS OCUPACIONES PARA LAS ENCUESTAS CASEN Y PIAAC ${ }^{1}$

\begin{tabular}{|c|l|l|}
\hline Numeración & \multicolumn{1}{|c|}{ Encuesta PIAAC } & \multicolumn{1}{c|}{ Encuesta CASEN } \\
\hline 1 & Gerentes & $\begin{array}{l}\text { Miembros del poder legislativo y ejecutivo y } \\
\text { gerentes }\end{array}$ \\
\hline 2 & Profesionales & Profesionales científicos e intelectuales \\
\hline 3 & Técnicos y profesionales asociados & Técnicos y profesionales de nivel medio \\
\hline 4 & Trabajadores de apoyo en oficina & Empleados de oficina \\
\hline 5 & Trabajadores de servicio y ventas & T. de servicio, venta de comercio y mercados \\
\hline 6 & Agricultura, silvicultura y pesca & Agricultores, agropecuarios y pesqueros \\
\hline 7 & Oficios y relacionados & Oficios \\
\hline 8 & Operarios de maquinaria y planta & $\begin{array}{l}\text { Operarios de instalaciones, maquinaria } \\
\text { y planta }\end{array}$ \\
\hline 9 & No calificados & No calificados \\
\hline
\end{tabular}

* Fuente: Elaboración propia.

1 El detalle del enlace por medio de las ocupaciones entre las bases PIAAC y CASEN está en el Anexo Tabla A.3. 
3.2.3. Medición de las diferencias salariares en sobreeducados y no sobreeducados, método de Propensity Score Matching (PSM)

En esta sección se abordará la metodología de PSM, para ello se definirá la condición de independencia o unconfoundedness, el modelo PROBIT necesario para calcular el propensity score (PS), el problema del vecino más cercano y el Average Treatment effect on Treatment (ATT).

PSM es una técnica de estimación no paramétrica que permite estimar ATT consistentemente, ya que dicho método reducirá el sesgo por variable omitida generado al comparar el grupo de controles (sobreeducados) y de tratamientos (no sobreeducados) que no son homólogos entre sí. Entonces, el objetivo del método es emular la asignación aleatoria del tratamiento en la muestra y para ello es necesario crear un contrafactual para cada tratado con un PS similar. Dicho en otras palabras, se seleccionará un grupo de control ideal, de tal manera que para cada tratado existe un control que es homólogo a este.

La condición de independencia o unconfoundedness es definida como la ortogonalidad entre la asignación de tratamiento y los grupos de control y tratados dado el PS. Esto se escribe como:

$$
T \perp Y(0), Y(1) \mid p(X)
$$

Donde $Y(0)$ e $Y(1)$ son los grupos de control y de tratados, respectivamente.

El PS es definido como la probabilidad de ser tratado dado un set de características. Esto se escribe como:

$$
p(x)=\operatorname{Pr}(T=1 \mid X=x)
$$

Los modelos de probabilidad no lineales clásicos pueden ser usados para calcular el PS. En esta investigación utilizamos el modelo PROBIT, según esta la probabilidad de estar sobreeducado es la siguiente:

$$
\operatorname{Pr}\left(D_{i}=1 \mid X_{i}\right)=y_{i}=\int_{-\infty}^{h\left(X_{i}\right)} \frac{1}{(2 \pi)^{\frac{1}{2}}} e^{-\frac{s^{2}}{2}} d s+\varepsilon_{i}
$$

Donde $h\left(X_{i}\right)=\beta_{0}+\beta X_{i}$ representa la función valuada en el vector $X_{i}$. Dicho vector es definido en el espacio de características del individuo, las que determinarían la probabilidad de estar sobreeducado para el individuo $i$. Además, el modelo probit o modelo PS es calculado usando soporte común en las variables.

Para esta investigación se seleccionarán las características utilizadas por McGuinness (2008), las que conformarán el vector $X_{i}$. Dichas características son agrupadas en 
dos tipos de variables: el primer grupo conformado por las variables dicotómicas y el segundo grupo conformado por variables discretas. Dichas variables quedan descritas en la Tabla 3.

\section{TABLA 3}

TABLA DE TIPO Y DESCRIPCION DE LAS VARIABLES DEL MODELO PROBIT

\begin{tabular}{|c|c|}
\hline \multicolumn{2}{|r|}{ Variables dicotómicas } \\
\hline Variable & Descripción \\
\hline Casado & Igual a uno si es casado e igual a 0 si es soltero cero cualquier otro tipo de relación \\
\hline Urbano & Igual a uno si vive en sector urbano e igual a cero si vive en sector rural \\
\hline Santiago & Igual a uno si vive en Santiago e igual a cero si viven en cualquier otro lugar \\
\hline Mujer & Igual a uno si es mujer e igual a cero cualquier otro caso \\
\hline Pública & $\begin{array}{l}\text { Igual a uno si trabaja en una empresa pública e igual a cero si trabaja de una } \\
\text { empresa privada }\end{array}$ \\
\hline $\begin{array}{l}\text { Educación } \\
\text { técnica }\end{array}$ & $\begin{array}{l}\text { Igual a uno si el trabajador posee estudios de nivel técnico e igual a cero si reporta } \\
\text { estudios universitarios o de postgrado }\end{array}$ \\
\hline Sindicato & Igual a uno si pertenece a un sindicato e igual a cero si no pertenece \\
\hline Extranjero & Igual a uno si no posee nacionalidad chilena e igual a cero si la posee \\
\hline $\begin{array}{l}\text { Carreras no } \\
\text { tradicionales }\end{array}$ & $\begin{array}{l}\text { Igual a cero si no reporta estudios referentes a las siguientes áreas: medicina, } \\
\text { educación, ciencias económicas, ciencias, matemáticas, ingenierías tradicionales, } \\
\text { derecho e igual uno si pertenece a dichas carreras }\end{array}$ \\
\hline $\mathrm{CRUCH}$ & $\begin{array}{l}\text { Igual a uno si el estudiante estudió en alguna universidad perteneciente al consejo } \\
\text { de rectores e igual a cero si estudió en alguna universidad privada }\end{array}$ \\
\hline \multicolumn{2}{|r|}{ Variables discretas } \\
\hline Variable & Descripción \\
\hline Edad & Edad del encuestado \\
\hline Experiencia & Años de experiencia del encuestado en su último trabajo \\
\hline
\end{tabular}

El método del vecino más cercano será usado como criterio con el que se seleccionará el grupo de control ideal. Dicho método plantea encontrar dos vectores, cuya norma sea la menor en un espacio o conjunto métrico. Para ello se utilizará el PS como indicador que nos señalará qué tan cerca o similares son dos o más vectores entre sí. Esto quiere decir que, si dos vectores son muy parecidos, sus PS lo serán también. Como norma vectorial, se usará la norma o distancia Euclidiana, la que se define como: 


$$
N\left(x_{p}, x_{t}\right)=\left(\sum_{i=1}^{n}\left(x_{p, i}-x_{t, i}\right)^{2}\right)^{\frac{1}{2}}
$$

Además se definirá para cada uno de los tratados una vecindad en torno a estos, en la que se congregan los tres controles cuya norma o distancia euclidiana es la menor respecto del tratado perteneciente a esta.

Finalmente se calculan las diferencias de salarios y de porcentajes de trabajadores con capacitación laboral entre sobreeducados y no sobreeducados. Para ello es utilizado el efecto del tratamiento en los tratados, ATT, como medida consistente para dichas diferencias. El ATT es definido como:

$$
\begin{aligned}
A T T=E[Y(1) & -Y(0) \mid T=1, p(X)] \\
& =E[Y(1) \mid T=1, p(X)]-E[Y(0) \mid T=1, p(X)]
\end{aligned}
$$

Donde, $E[Y(1) \mid T=1, p(X)]$ es el promedio de los promedios de los salarios o capacitaciones de los controles pertenecientes a cada una de las vecindades y $E[Y(0) \mid T=1, p(X)]$ es el promedio de los salarios o capacitaciones de los tratados pertenecientes a cada una de las vecindades.

\section{RESULTADOS}

En la siguiente sección se detallarán los principales resultados de esta investigación. Dichos resultados se dividirán en tres apartados. En el primer apartado se detallarán los porcentajes de trabajadores sobreeducados con estudios superiores del total de trabajadores con estudios superiores divididos por año y género, cohorte etaria, ocupación u oficio y tipo de universidad. En el segundo apartado se detallará el modelo PROBIT obtenido, mostrando los efectos marginales de las variables a destacar. En el tercer apartado se mostrarán los resultados de las diferencias salariales y de capacitación entre sobreeducados y adecuadamente educados.

Los resultados de la incidencia de la sobreeducación por año y género se pueden observar en la Figura 2, la que muestra que del total de trabajadores hombres con estudios superiores, $38 \%$ se consideran sobreeducados y del total de trabajadoras con estudios superiores $33 \%$ se consideran sobreeducadas. Es importante destacar que entre el 2003 y 2015 los resultados son bastante estables, ya que del total de trabajadores hombres con estudios superiores, el porcentaje de sobreeducados oscila entre $36 \%$ y $39 \%$, y del total de trabajadoras con estudios superiores el porcentaje de sobreeducadas oscila entre $33 \%$ y $37 \%$. 


\section{FIGURA 2}

\section{GRAFICO DE SOBREEDUCACION POR GENERO Y AÑO}

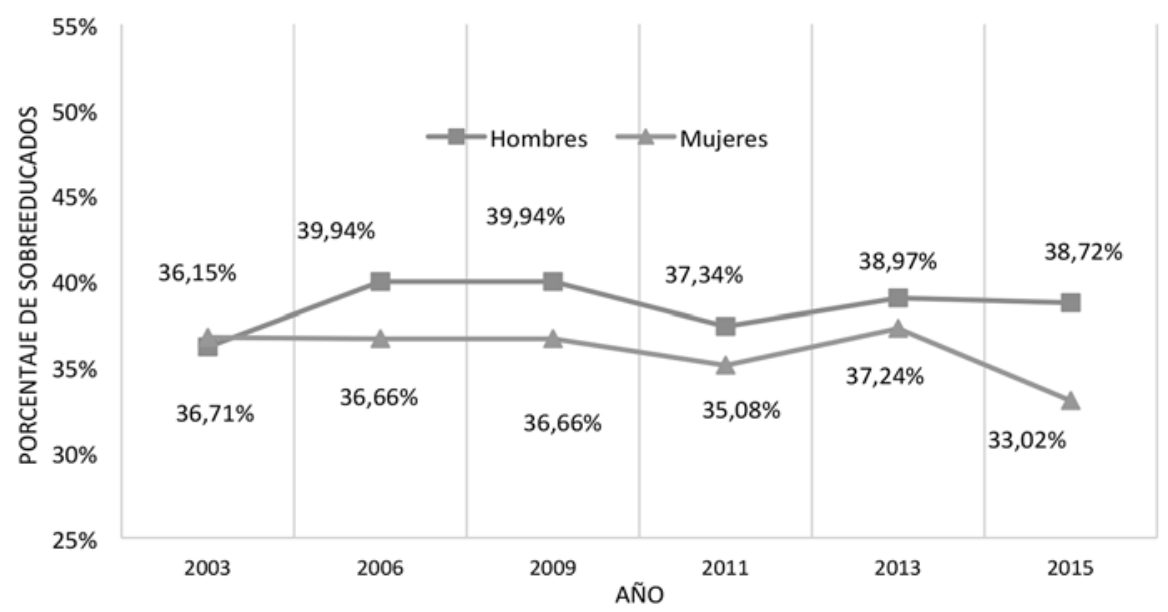

* Fuente: CASEN 2003-2015.

La incidencia de la sobreeducación por tramo etario se puede observar en la Figura 3, esta evidencia un descenso en el porcentaje de sobreeducados del total de trabajadores con estudios superiores entre los 20 y 30 años, una relativa estabilidad en este porcentaje entre los 30 y 40 años y un ascenso de este porcentaje entre los 40 y 50 años. Estos resultados son similares cualitativamente a los expuestos por Farooq (2016) usando datos para Estados Unidos. En efecto, el autor encuentra que la sobreeducación de los trabajadores es decreciente en los primeros años de vida laboral, ya que en estos años la acumulación de habilidades laborales adquiridas por parte del trabajador por medio de la experiencia o capacitaciones en el trabajo harían que este encuentre empleos acordes a sus estudios. Por otro lado, que el porcentaje de sobreeducados sea creciente en los últimos años de vida laboral refleja que dichas habilidades laborales se deprecian con la edad. En conclusión, el comportamiento de la sobreeducación por la edad adquiere una forma de "U".

La incidencia de la sobreeducación por tipo de ocupación u oficio más elevada del 2015 es para trabajadores que desempeñan labores de poder ejecutivo, técnicas y de oficina. Dichos porcentajes se pueden observar en la Figura 4, los que son los siguientes: del total de trabajadores con estudios superiores que desempeñan labores en el poder ejecutivo, $37 \%$ son sobreeducados; del total de trabajadores con estudios superiores que desempeñan labores técnicas, $17 \%$ son sobreeducados; y del total de trabajadores con estudios superiores que desempeñan labores de oficina, $21 \%$ son 
sobreeducados. Además, para las ocupaciones técnicas y de oficina este mayor porcentaje se explicaría por los trabajadores con títulos universitarios que preferirían este tipo de ocupaciones u oficios que requieren menos calificaciones que las ya obtenidas, en contraste a otro tipo de ocupaciones que requieran aún menos calificaciones que las ya mencionadas.

\section{FIGURA 3}

\section{GRAFICO DE SOBREEDUCACION POR TRAMO ETARIO}

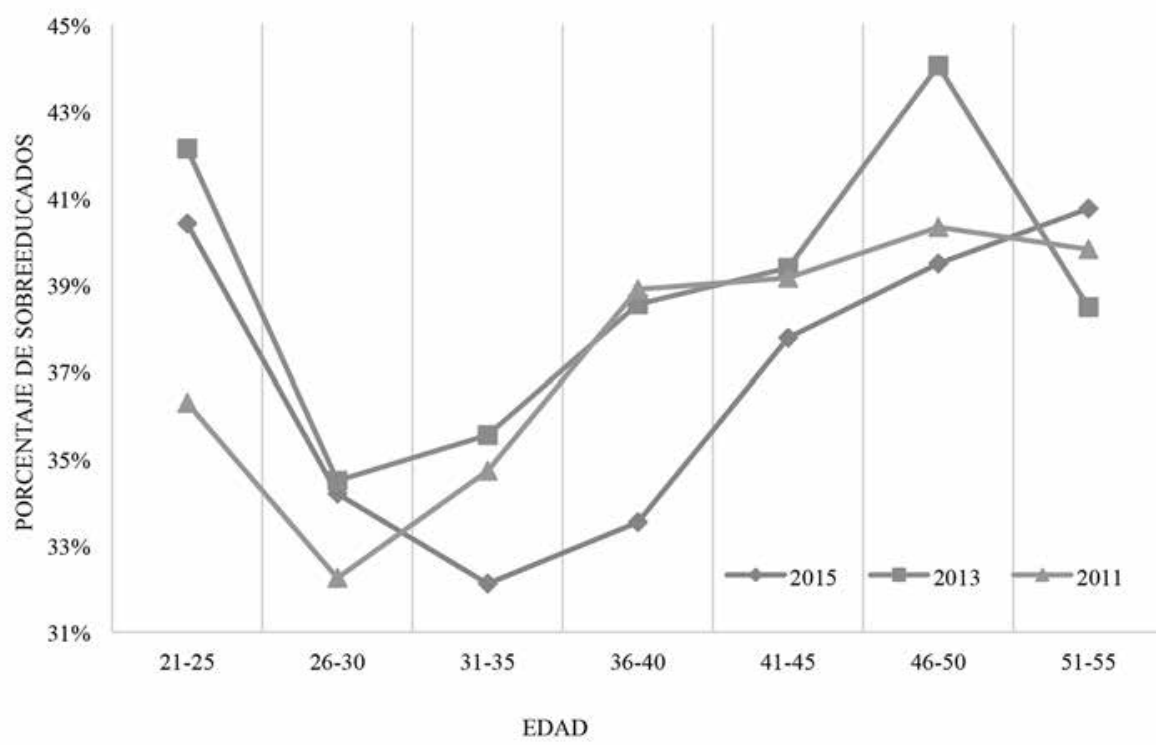

* Fuente: CASEN 2011-2015.

Como se observa en la Figura 5, las incidencias de sobreeducación por tipo de universidad de egreso en Chile para el 2015 son las siguientes: 16\% del total de trabajadores egresados de universidades privadas se consideran sobreeducados y $10 \%$ para el total de trabajadores egresados de universidades pertenecientes al CRUCH. Para el 2013 el $28 \%$ del total de trabajadores egresados de universidades privadas se considera sobreeducado y $14 \%$ para el total trabajadores egresados de universidades pertenecientes al CRUCH. Dichas cifras nos dan a entender que quienes están más propensos a estar sobreeducados son quienes estudian en universidades privadas. Esto da a entender que la calidad de la institución educacional puede jugar un rol importarte en la correcta inserción laboral de quienes estudian en dichas instituciones. Además, 
como se logra observar en la Figura 6, las incidencias de sobreeducación por tipo de universidad de egreso en Santiago para el 2015 son las siguientes: 15\% del total de trabajadores sobreeducados egresados de universidades privadas se consideran sobreeducados y $9 \%$ para trabajadores egresados de universidades pertenecientes al CRUCH, y en el 2013 son 34\% del total de trabajadores egresados de universidades privadas los que se consideran sobreeducados y $9 \%$ para trabajadores egresados de universidades pertenecientes al CRUCH. Finalmente, es posible señalar que en total de trabajadores con ocupaciones científicas o intelectuales estudiado, el porcentaje de sobreeducados es cero, ya que todas estas ocupaciones reportaron requerimientos de educación universitaria.

\section{FIGURA 4}

\section{GRAFICO DE SOBREEDUCACION POR TIPO DE OCUPACION}

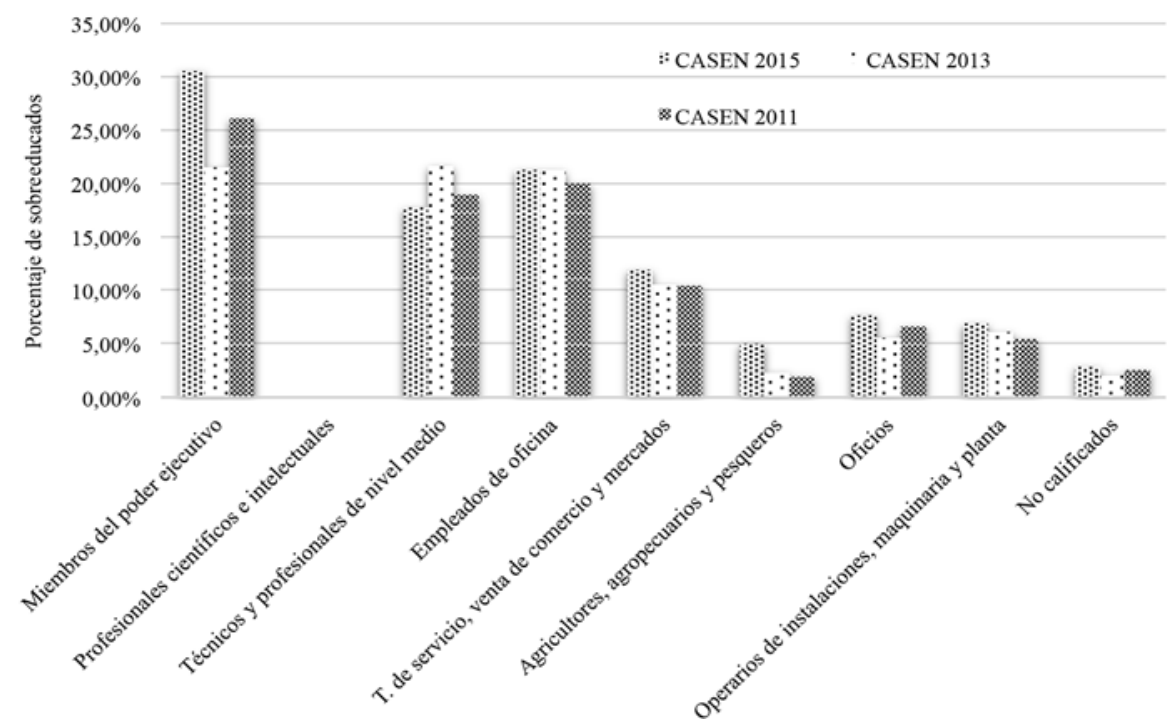

* Fuente: CASEN 2011 al 2015.

La evidencia aportada por el modelo PROBIT se expondrá dividida en tres cohortes etarias: 20 a 30 años, 30 a 40 años y 40 a 50 años. Concretamente para esta investigación, es de interés saber cuáles son los determinantes que explicarían la probabilidad de estar sobreeducado y cómo estos determinantes cambian con las cohortes etarias. Los resultados del modelo PROBIT para las tres cohortes se presentan en la Tabla 4, 


\section{FIGURA 5}

GRAFICO DE SOBREEDUCACION POR TIPO DE UNIVERSIDAD PARA CHILE

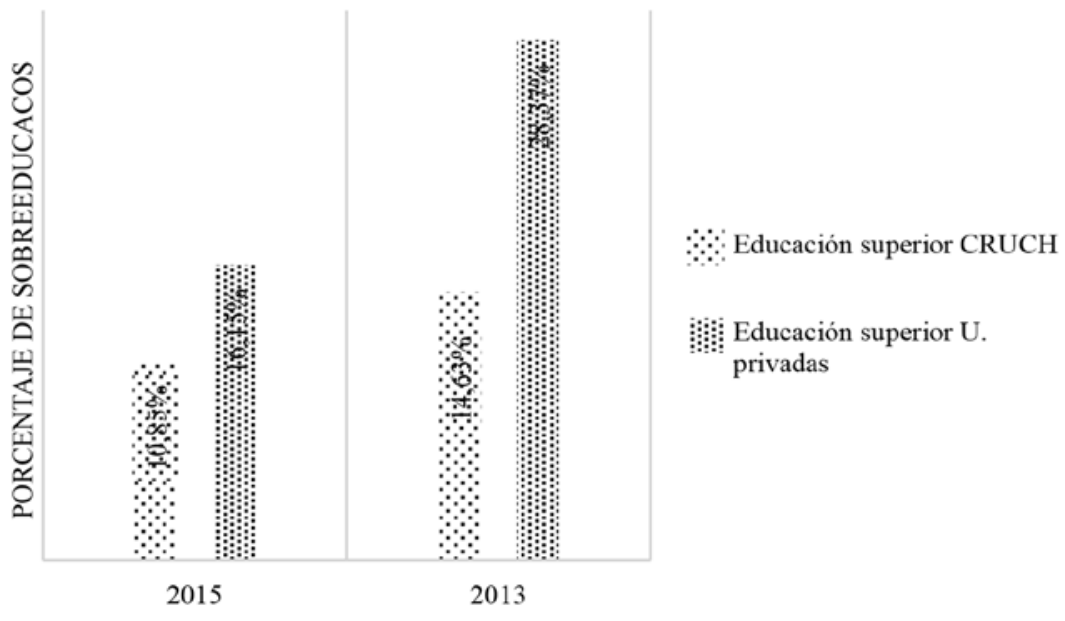

* Fuente: CASEN 2013-2015.

\section{FIGURA 6}

GRAFICO DE SOBREEDUCACION POR TIPO DE UNIVERSIDAD PARA SANTIAGO

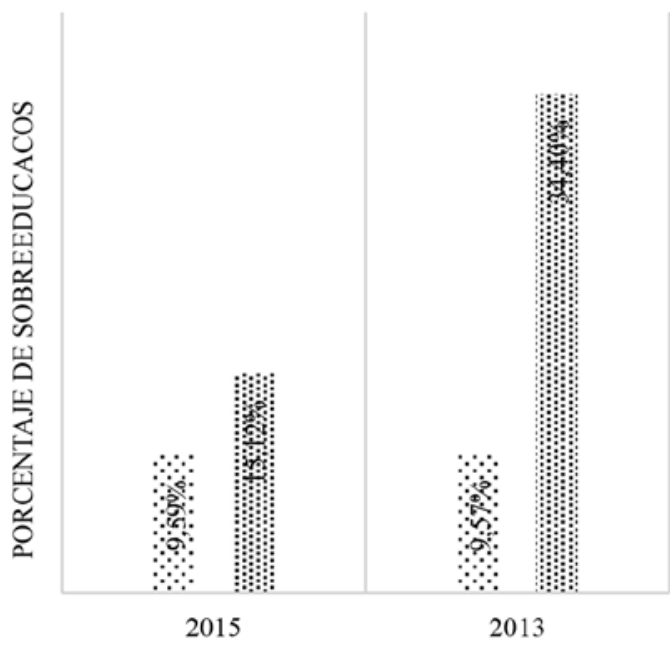

$\because$ Educación superior $\mathrm{CRUCH}$

Educación superior U. privadas

* Fuente: CASEN 2013-2015. 


\section{TABLA 4}

RESULTADOS DEL MODELO PROBIT PARA LA MUESTRA CASEN 2015

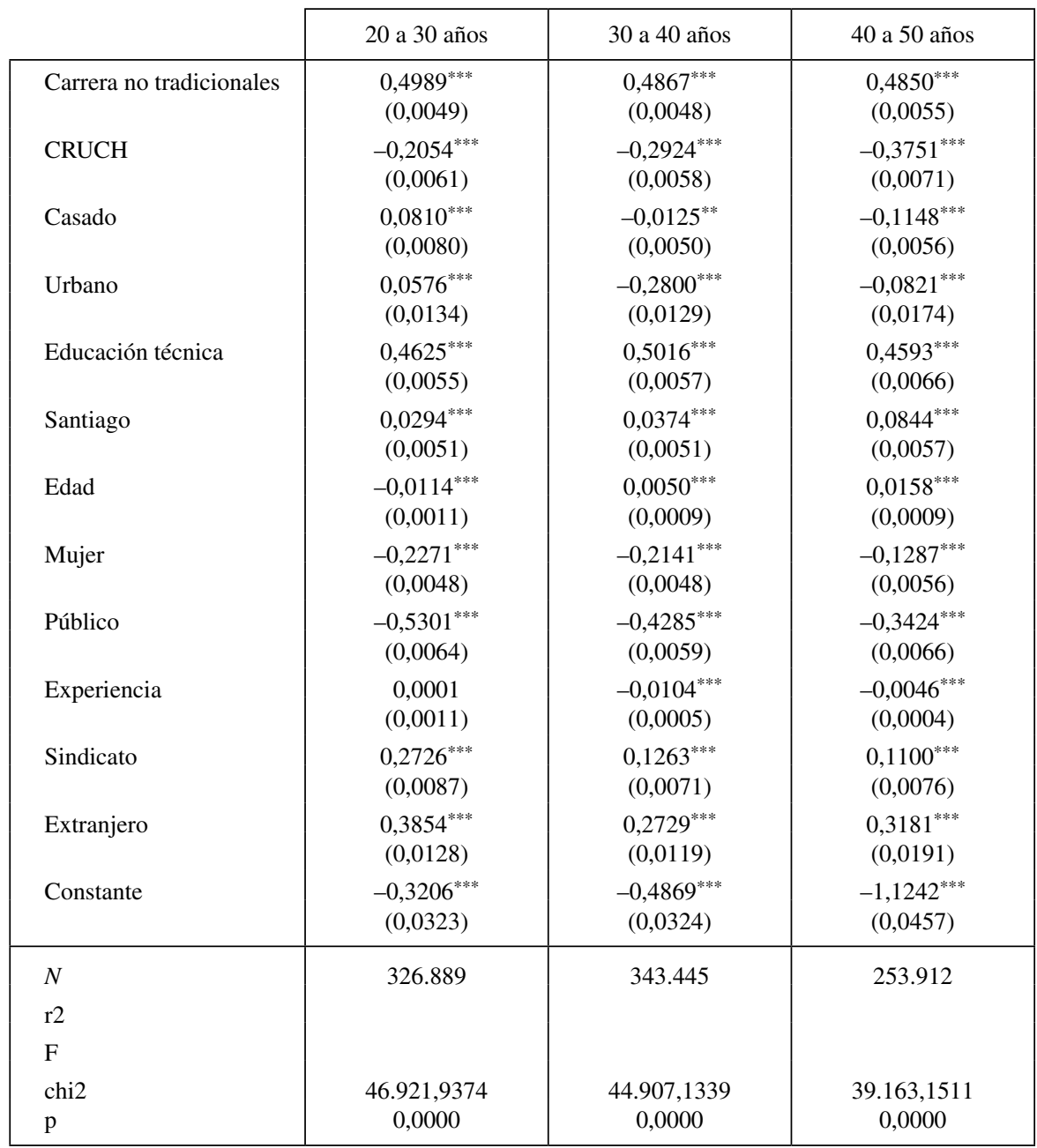

Desviación estándar en paréntesis.

${ }^{*} p<0,1,{ }^{* *} p<0,05,{ }^{* * *} p<0,01$

de estos es importante destacar que quienes están más propensos a estar sobreeducados, según programa educativo para todos los tramos etarios, son los titulados de carreras no tradicionales y carreras técnicas. También, quienes están más propensos a estar 
sobreeducados por tipo de institución de egreso para todos los tramos etarios son titulados de institutos profesionales y titulados de universidades privadas. Estos resultados sugieren que lo que predispondría a estar sobreeducado es la calidad tanto de los programas educativos como de las instituciones educativas, ya que programas educativos o institutos educativos no reconocidos darían una mala señalización a los empleadores a la hora de contratar trabajadores pertenecientes a dichos programas o instituciones. Por otro lado, el efecto marginal según edad y experiencia en la probabilidad de estar sobreeducado por cohorte etario será negativo en las cohortes etarias de 20 a 30 años, casi nulo en las cohortes etarias de 30 a 40 años y positivo en las cohortes etarias de 40 a 50 años. Esto evidencia que la experiencia y otros tipos de atributos adquiridos en el trabajo adquieren una relevancia importante en los jóvenes recién iniciados en el mundo laboral. Sin embargo, estos atributos sufrirían una desvalorización a medida que el trabajador envejece. Farooq (2016) explica esto como una depreciación de los atributos adquiridos en el trabajo por parte del trabajador. En cuanto a trabajadores pertenecientes a empresas públicas, los resultados señalan una menor propensión a estar sobreeducado en comparación a sus homólogos pertenecientes a empresas privadas, lo que evidenciaría la mejor asignación de empleo de la mano de obra calificada en empresas de carácter público. Respecto de los trabajadores que reportaron pertenecer a un sindicato, estos evidenciaron ser más propensos a estar sobreeducados que sus pares que no pertenecen a un sindicato, esto evidencia que el ajuste en los mecanismos de producción por parte de la empresa para poder aprovechar de mejor manera su mano de obra calificada se vería perjudicado en presencia de sindicatos. Además, un resultado evidenciado en esta investigación y acorde con lo expuesto en la literatura referente a sobreeducación, es la menor propensión a la sobreeducación en mujeres que en hombres, lo que evidenciaría un mejor calce en la asignación de empleos en mujeres con estudios superiores que en hombres con el mismo nivel de estudio. Dicho fenómeno podría ser explicado por una mayor elasticidad salario-hora en la oferta laboral femenina calificada, la que haría un mejor calce entre estudios alcanzados y estudios requeridos por la labor que se desempeña. También, otro resultado a destacar es la mayor propensión a estar sobreeducado de los trabajadores extranjeros con estudios superiores en contraste a sus pares nacionales. Esto puede ser explicado en parte a un mal reconocimiento de los estudios extranjeros por parte de los empleadores. Sin embargo, esta mayor propensión a estar sobreeducado cae a mayor edad: este fenómeno puede ser explicado por la acumulación de experiencias o formación laboral con la edad por parte de los trabajadores extranjeros, generando así una correcta asignación laboral. Finalmente, los efectos en las propensiones a estar sobreeducado si los trabajadores son casados para cada una de las cohortes son los siguientes: positivo para la cohorte etaria de 20 a 30 años y negativo para las cohortes etarias de 30 a 40 años y de 40 a 50 años. Esto evidencia una asignación mejor de empleos en trabajadores casados en los tramos etarios de 30 a 40 años y de 40 a 50 años que en la cohorte etaria de 20 a 30 años. 
Como se observa en la Tabla 5 para hombres y en la Tabla 6 para mujeres, el salario promedio obtenido por los trabajadores sobreeducados tanto para hombres como mujeres, ambos con estudios superiores, es menor que el salario promedio percibido por los trabajadores no sobreeducados del mismo género para todas las cohortes etarias. Esto es evidenciado en una diferencia negativa para el salario promedio percibido por los trabajadores con estudios superiores sobreeducados menos el salario promedio percibido por los trabajadores con estudios superiores no sobreeducados. En consecuencia, la menor retribución salarial para los sobreeducados evidenciaría al empleo como el determinante principal del salario y no la productividad. Además, dicha diferencia salarial en ambos grupos sugiere que las empresas no serían capaces, a lo menos en el corto plazo, de adaptar sus métodos productivos con el fin de aprovechar la capacidad total de la mano de obra calificada a su disposición. Este fenómeno puede ser explicado por la rigidez salarial (contratos colectivos y negociaciones colectivas) e imperfecciones en el mercado laboral (información asimétrica, entre otras), las que impedirían a lo menos en el corto plazo realizar ajustes al factor trabajo. Además, es oportuno destacar que la evolución de la variación porcentual masculina de la diferencia salarial ya mencionada como porcentaje del salario promedio en los hombres con estudios superiores y sobreeducados, experimenta un abrupto aumento en las cohortes de 30 a 40 años y de 40 a 50 años respecto de la cohorte etaria de 20 a 30 años. Esto podría explicar una convergencia en los salarios, lo que podría evidenciar una mejor asignación por edad para los hombres. Sin embargo, la evolución de la variación porcentual femenina de la diferencia salarial ya mencionada como porcentaje del salario promedio de las mujeres con estudios superiores y sobreeducadas se mantiene constante en las cohortes, fenómeno que evidenciaría una mala asignación del empleo a pesar de la edad en mujeres. Esto es explicado en parte por la mala señalización de la experiencia o habilidades adquiridas en el empleo para las mujeres. También, otro resultado a destacar es que solo las mujeres en las cohortes de 20 a 30 años y 30 a 40 años mostraron diferencias significativas en la proporción de capacitación laboral de trabajadoras sobreeducadas con estudios superiores, ya que las cohortes mostraron que dichas trabajadoras son menos capacitadas que sus homólogas no sobreeducadas, lo que apoya la hipótesis que postula que la sobreeducación va inversamente ligada a la experiencia y capacitación laboral, refutando la visión de los modelos de competencia laboral ${ }^{2}$. Además, es importante destacar que los resultados son disímiles entre hombres y mujeres, ello refuta que la estrategia de identificación al dividir por género la muestra CASEN 2015 fue la adecuada.

2 En el Anexo se realiza un test de robustez, el que consiste en realizar el método de PSM a 5 vecinos más cercanos. Los resultados de este test son similares a los resultados del PSM a 3 vecinos. 


\section{TABLA 5}

\section{RESULTADOS DE LA METODOLOGIA PSM PARA LA MUESTRA DE HOMBRES DIVIDIDA EN TRAMOS ETARIOS, CASEN 2015}

\begin{tabular}{|l|c|c|c|}
\hline \multicolumn{1}{|c|}{ Vecinos (3) } & 20 a 30 años & 30 a 40 años & 40 a 50 años \\
\hline Tratados salario hora & $3.079,596$ & $4.693,063$ & $5.711,513$ \\
Tratados - controles, Unmatched & $-1.707,51$ & $-1.857,66$ & $-1.972,14$ \\
& $(-5,37)$ & $(-8,08)$ & $(-3,81)$ \\
Tratados - controles, ATT & $-1.448,45$ & $-887,306$ & $-796,584$ \\
& $(-2,86)$ & $(-3,35)$ & $(-1,21)$ \\
Variación porcentual & $-47,03 \%$ & $-18,91 \%$ & $-13,95 \%$ \\
Tratados capacitación & 0,26 & 0,32 & 0,34 \\
Tratados - controles, Unmatched & 0,06 & 0,05 & $-0,07$ \\
Tratados - controles, ATT & $(-2,76)$ & $(-6,15)$ & $(-2,87)$ \\
& $-0,04$ & $-0,01$ & $-0,05$ \\
& $(-1,46)$ & $(-0,23)$ & $(-1,62)$ \\
\hline
\end{tabular}

Estadístico T en paréntesis.

\section{TABLA 6}

\section{RESULTADOS DE LA METODOLOGIA PSM PARA LA MUESTRA DE MUJERES} DIVIDIDA EN TRAMOS ETARIOS, CASEN 2015

\begin{tabular}{|l|c|c|c|}
\hline \multicolumn{1}{|c|}{ Vecinos (3) } & 20 a 30 años & 30 a 40 años & 40 a 50 años \\
\hline Tratados salario hora & $2.690,62$ & $3.579,48$ & $3.609,64$ \\
Tratados - controles, Unmatched & $-886,95$ & $-1.219,79$ & $-1.365,57$ \\
& $(-8,17)$ & $(-5,18)$ & $(-7,05)$ \\
Tratados - controles, ATT & $-724,22$ & $-1.255,38$ & $-1.191,87$ \\
& $(-5,73)$ & $(-3,98)$ & $(-4,89)$ \\
Variación porcentual & $-26,92 \%$ & $-35,07 \%$ & $-33,02 \%$ \\
Tratados capacitación & 0,24 & 0,29 & 0,30 \\
Tratados - controles, Unmatched & 0,12 & 0,12 & $-0,14$ \\
Tratados - controles, ATT & $(-6,15)$ & $(-5,90)$ & $(-6,04)$ \\
& $-0,09$ & $-0,08$ & $-0,05$ \\
& $(-3,67)$ & $(-3,04)$ & $(-1,50)$ \\
\hline
\end{tabular}

Estadístico T en paréntesis. 


\section{CONCLUSION}

La incidencia de trabajadores con estudios superiores sobreeducados para el 2015 es aproximadamente de 38\% del total de la población masculina y $33 \%$ del total de la población femenina. Dichos resultados nos dan a entender que más de un tercio del total de trabajadores con estudios superiores trabajan en empleos que requieren un nivel educacional inferior al adquirido. Dichas cifras nos deben preocupar, pero más aún nos debe preocupar qué es lo que hay detrás de ellas.

La evidencia aportada en esta investigación sugiere que el fenómeno de la sobreeducación puede ser explicado por la calidad en los programas o tipo de universidades, ya que los resultados indican que del total de trabajadores con estudios universitarios, $16 \%$ son trabajadores sobreeducados titulados de universidades privadas y $10 \%$ son titulados de universidades pertenecientes al CRUCH. Además, quienes están más propensos a estar sobreeducados son quienes estudian carreras técnicas o carreras no tradicionales o trabajadores titulados de universidades privadas o institutos profesionales. Otro resultado importante es la forma de "U" de la sobreeducación mediante la edad obtenida en esta investigación. Dicho fenómeno es acorde a lo expuesto por Farooq (2016) y la explicación a esto sería que atributos como las habilidades en el trabajo (capacitaciones y experiencia laboral) harían que los trabajadores jóvenes de 20 a 30 años encuentren trabajos acordes a sus estudios, observando así un menor número de sobreeducados a medida que estos avanzan en edad. Sin embargo, para trabajadores adultos entre 40 y 50 años dichos atributos se desvalorizan, observando así un mayor número de sobreeducados a medida que avanzan en edad. Dicho fenómeno es evidenciado en los resultados aportados por el modelo PROBIT realizado en esta investigación, ya que la variación en la propensión a estar sobreeducado para un año adicional de edad y la experiencia para las cohortes son negativas en la cohorte de 20 a 30 años, casi nulas en la cohorte de 30 a 40 años y positivo en la cohorte de 40 a 50 años.

Finalmente, los sobreeducados exhiben menores remuneraciones que los no sobreeducados, lo que refuta la idea de que la remuneración queda determinada por el empleo y no por la capacidad o productividad potencial de dicho trabajador. Más aún, la productividad o las capacidades de los trabajadores quedarían determinadas por el tipo de empleo. En conclusión, los resultados expuestos refutarían la idea de que el comportamiento de la sobreeducación y el mercado laboral chileno se ajusta más a la visión de los modelos de competencia laboral. Además, solo el grupo de trabajadoras con estudios superiores, no sobreeducadas y pertenecientes a las cohortes femeninas de 20 a 30 años y 30 a 40 años, demostró tener una mayor proporción de integrantes capacitadas en comparación a sus homólogas sobreeducadas respectivas, refutando así la idea de que las trabajadoras capacitadas serían las que están menos sobreeducadas.

Los resultados expuestos en el presente trabajo sugieren que la calidad de la educación es fundamental para la correcta inserción laboral de los trabajadores. Las 
reformas y futuras políticas en materia educacional debiesen velar por la equidad en la calidad de las instituciones de educación superior. En conclusión, generar políticas que faciliten la adquisición de capacidades laborales es primordial.

\section{BIBLIOGRAFIA}

ALBA-RAMIREZ, A. (1993). "Mismatch in the Spanish labor market". Journal of Human Resources 28 (2): 259-278.

BATTU, H. y SLOANE, P. (2000). "Overeducation and crowding out in Britain. In Borghans and de Grip (eds), The Overeducated Worker”. Cheltenham: Edward Elgar: 157-175.

BECKER, G. "Human Capital: A Theoretical and Empirical Analysis with Special Reference to Education". New York: Columbia University Press.

BRYNIN, M. (2002). “Overqualification in Employment”. Work, Employment \& Society 16 (4): 637-54.

BUCHEL, F. y VAN HAM, M. (2002). "Overeducation, Regional Labour Markets and Spatial Flexibility”. IZA Discussion Paper $\mathrm{N}^{\circ} 424$.

CATTANI, L.; GUIDETTI, G.; PREDRINI, G. (2014). "Assessing the incidence and wage effects of overeducation among Italian graduates using a new measure for educational requirements". Working Papers wp939, Dipartimento Scienze Economiche, Universita' di Bologna.

CHEVALIER, A. (2003). "Measuring overeducation". Economica 70: 509-531.

DALY, M., DUCHEL, F. y DUNCAN, G. (2000). "Premiums and penalties for surplus and deficit education: evidence from the United States and Germany". Economics of Education Review 19: 169-178.

DOLADO, J., JANSEN, M., y JIMENO, J. (2009). "On the job-search in a matching model with heterogeneous jobs and workers". Economic Journal, 119: 200-228.

DOLTON, P. y VIGONOLES, A. (2000). "The incidence and effects of overeducation in the UK graduate labour market". Economics of Education Review 19: 179-198.

DUMONT, J.-C. y O. MONSO (2007), "Matching Educational Background and Employment: a Challenge for Immigrants in Host Countries", International Migration Outlook: 131-159.

DUNCAN, G. y HOFFMAN, S. (1981). "The incidence and wage effects of overeducation". Economics of Education Review, 1 (1): 75-86.

FAROOQ, A. (2016). "The U-shape of Over-education? Human Capital Dynamics \& Occupational Mobility over the Life Cycle”. 2016 Papers pfa484, Job Macket Papers.

FLISI, S.; GOGLIO, V.; MERONI, E.C. et al. Soc Indic Res (2017) 131: 1211.

GALASI, P. (2008). "The effect of educational mismatch on wages for 25 countries". Budapest Working Papers on the Labour Market BWP - 2008/8.

GREEN, F.; MCLNTOSH, S. y VIGNOLOSM, A. (1999). "Overeducation and skills-clarifying the concepts". Technical report.

GREEN, F. y HENSEKE, G. (2016). "Should governments of OECD countries worry about graduate over-education?”. Oxford Review of Economic Policy, Volume 32 (4): 514-537.

GROENEVELD, S. y HARTOG, J. (2004). "Overeducation, wages and promotions within thefirm". Labour Economics 11: 701-714.

GROOT, W. (1996). "The incidence and returns to overeducation in the UK". Applied Economics 28: 1345-1350.

GROOT, W. y VAN DEN BRINK, H. (2000a). "Skill mismatches in the Dutch labor market". International Journal of Manpower 21 (8): 584-595.

GROOT, W. y MAASEEN VAN DEN BRINK, H. (2000a). "Overeducation in the labor market: A metaanalysis". Economics of Education Review, 19 (2): 149-158.

HARTOG, J. y OOSTERBEEK, H. (1988). "Education, allocation and earnings in the Netherlands: overschooling?". Economics of Education Review 7 (2): 185-194.

HARTOG, J. (2000). "Over-education and earnings: where are we, where should we go?". Economics of Education Review, 19 (2): 131-147. 
HECKMAN, J.; LOCHNER, J. y TODD, P. (2003). "Fifty Years of Mincer Regressions". IZA DP, № 775.

KORPI, T. y TAHLIN, M. (2009). "Educational mismatch, wages, and wage growth: overeducation in Sweden, 1974-2000". Labour Economics, 16 (2): 183-93.

LEUVEN, E. y OOTERBEEK, H. "Overeducation and Mismatch in the Labor Market". Handbook of the Economics of Education 4: 283-326.

MCGUINNESS, S. (2003a). "Graduate overeducation as a sheepskin effect: evidence from Northern Ireland". Applied Economics 35: 597-608.

MCGUINNESS, S. (2006). "Overeducation in the labour market". Journal of Economic Surveys, 20 (3): 387-418.

MENDES DE OLIVEIRA, M.; SANTOS, M.C. y KIKER, B. (2000). "The role of human capital and technological change in overeducation". Economics of Education Review 19: 199-206.

MINCERM, J. (1974). "Schooling, Experience and Earnings". New York: Columbia University Press.

ORTIZ, L. (2010). "Not the Right Job, but a Secure One Over-Education and Temporary Employment in France, Italy and Spain". Work, Employment \& Society 24 (1): 47-64.

RUMBERGER, R. (1987). "The impact of surplus education on productivity and earnings". Journal of Human Resources 22 (1): 24-50.

SALA, G. (2011). "Approaches to Skills Mismatch in the Labour Market: A Literature Review". Papers. Revista de Sociología, 96 (4): 1025-1045.

SICHERMAN, N. (1991). ““'Overeducation” in the labour market”. Journal of Labor Economics 9 (2): 101-122.

SLOANE, P.; BATTU, H. y SEAMAN, P. (1999). "Overeducation, undereducation and the British Labour market”. Applied Economics 31: 1437-1453.

SLOANE, P. (2003). "Much ado About Nothing? What does the Overeducation Literature Really tell us". In Buchel, F.; De Grip, A., and Mertens, A., editors, Overeducation in Europe; Current issues in theory and policy, pp. 11-45. Edward Elgar.

TSANG, M. y LEVIN, H. (1985). "The Economics of Overeducation". Economics of Education Review 4 (2): 93-104.

THUROW, L. (1975). Generating Inequality. New York: Basic Books.

VAHEY, S. (2000). "The great Canadian training robbery: evidence on the returns to educational mismatch". Economics of Education Review 19: 219-227.

VAN DER VELDEN, R. y VAN SOORENBIRG, M. (2000). "The measurement of overeducation and undereducation: self-report vs job-analyst method". Les Cahiers de Lamas.

VERDUGO, R y VERDUGO, N. (1989). "The impact of surplus schooling on earnings". Journal of Human Resources 24 (4): 629-643. 


\section{APENDICE}

\section{REDUCCION DE SESGO MEDIANTE EL METODO PSM}

\section{FIGURA A.1}

GRAFICO DE REDUCCION DE SESGO MEDIANTE EL METODO PSM PARA LA MUESTRA DE HOMBRES DE 20 A 30 AÑOS

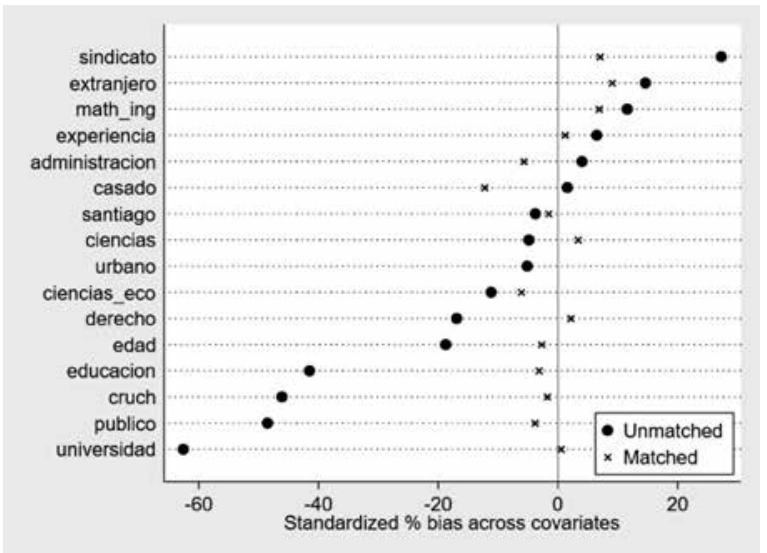

* Muestra CASEN 2015.

FIGURA A.2

GRAFICO DE REDUCCION DE SESGO MEDIANTE EL METODO PSM PARA LA MUESTRA DE HOMBRES DE 30 A 40 AÑOS

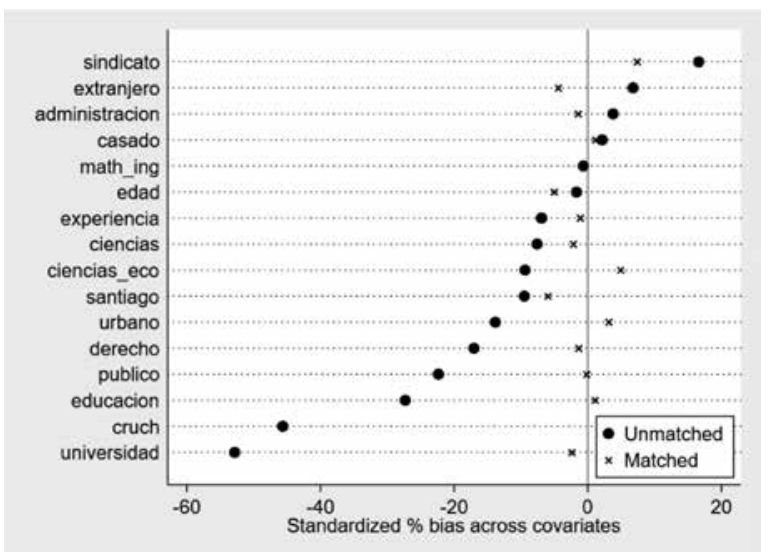

* Muestra CASEN 2015. 
FIGURA A.3

GRAFICO DE REDUCCION DE SESGO MEDIANTE EL METODO PSM PARA LA MUESTRA DE HOMBRES DE 40 A 50 AÑOS

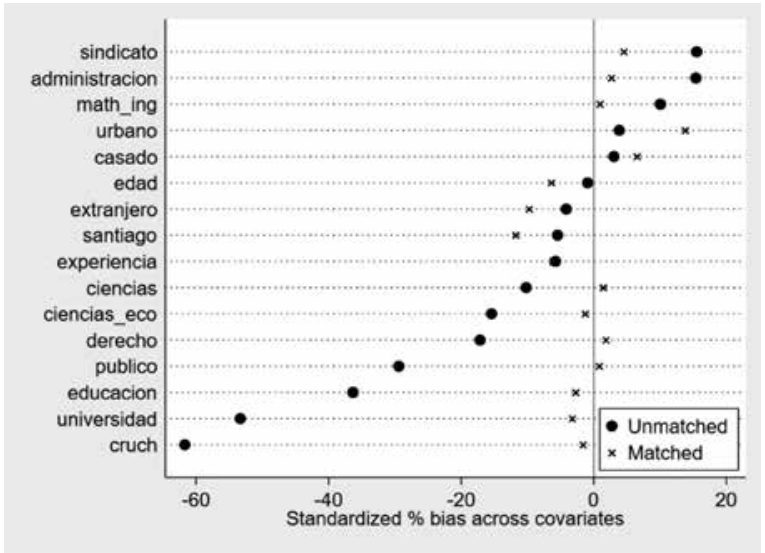

* Muestra CASEN 2015

FIGURA A.4

GRAFICO DE REDUCCION DE SESGO MEDIANTE EL METODO PSM PARA LA MUESTRA DE MUJERES DE 20 A 30 AÑOS

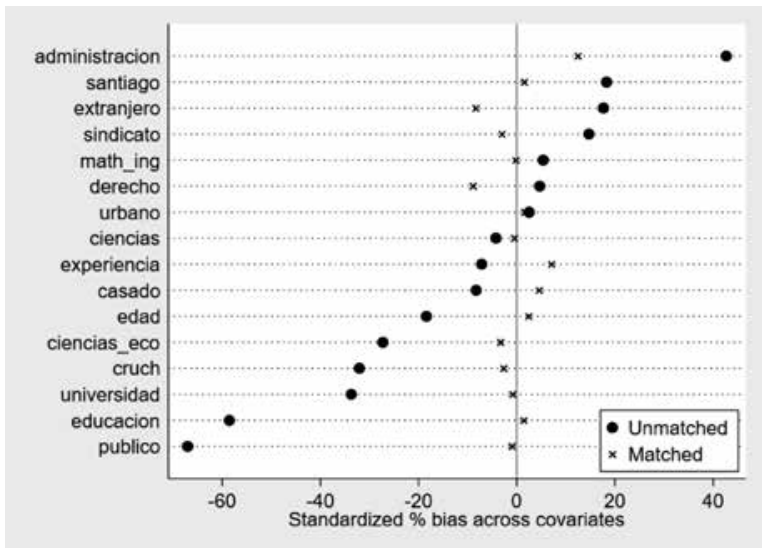

* Muestra CASEN 2015. 


\section{FIGURA A.5}

\section{GRAFICO DE REDUCCION DE SESGO MEDIANTE EL METODO PSM} PARA LA MUESTRA DE MUJERES DE 30 A 40 AÑOS

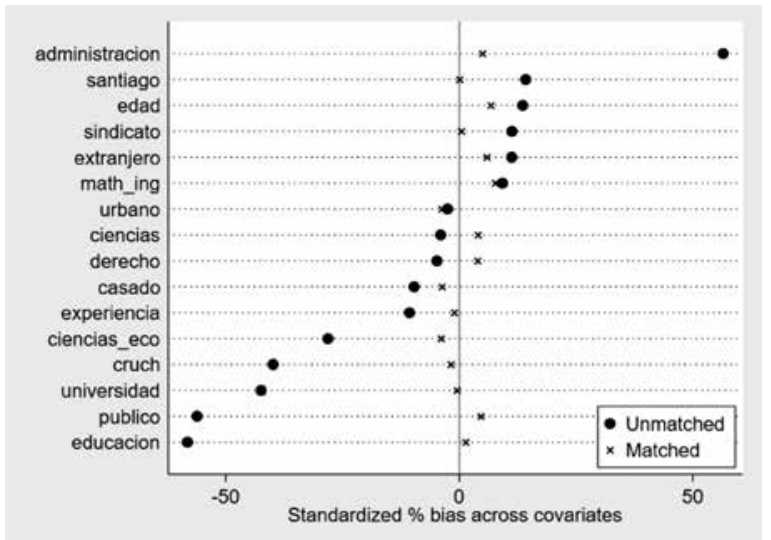

* Muestra CASEN 2015.

FIGURA A.6

GRAFICO DE REDUCCION DE SESGO MEDIANTE EL METODO PSM PARA LA MUESTRA DE MUJERES DE 40 A 50 AÑOS

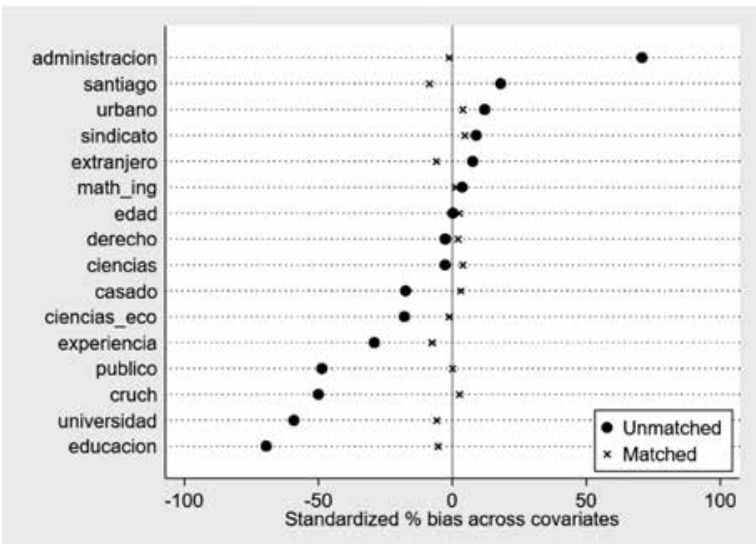

* Muestra CASEN 2015. 


\title{
RESULTADOS DE PSM A CINCO VECINOS MAS CERCANOS
}

\author{
TABLA A.1
}

RESULTADOS PSM A CINCO VECINOS, PARA LA MUESTRA DE HOMBRES DIVIDIDA POR TRAMOS ETARIOS, CASEN 2015

\begin{tabular}{|l|c|c|c|}
\hline \multicolumn{1}{|c|}{ Vecinos (5) } & 20 a 30 años & 30 a 40 años & 40 a 50 años \\
\hline Tratados salario hora & $3.079,60$ & $4.693,06$ & $5.711,51$ \\
Tratados - controles, Unmatched & $-1.707,51$ & $-1.857,66$ & $-1.972,14$ \\
& $(-5,37)$ & $(-8,08)$ & $(-3,81)$ \\
Tratados - controles, ATT & $-1.262,18$ & $-865,80$ & $-780,98$ \\
& $(-2,85)$ & $(-3,45)$ & $(-1,22)$ \\
Variación porcentual & $-40,99 \%$ & $-18,45 \%$ & $-13,67 \%$ \\
Tratados capacitación & 0,26 & 0,32 & 0,34 \\
Tratados - controles, Unmatched & $-0,06$ & $-0,05$ & $-0,07$ \\
& $(-2,76)$ & $(-6,15)$ & $(-2,87)$ \\
Tratados - controles, ATT & $-0,03$ & 0,00 & $-0,03$ \\
& $(-1,01)$ & $(-0,15)$ & $(-1,05)$ \\
\hline
\end{tabular}

Estadístico T en paréntesis.

\section{TABLA A.2}

\section{RESULTADOS PSM A CINCO VECINOS, PARA LA MUESTRA DE MUJERES DIVIDIDA POR TRAMOS ETARIOS, CASEN 2015}

\begin{tabular}{|l|c|c|c|}
\hline \multicolumn{1}{|c|}{ Vecinos (5) } & 20 a 30 años & 30 a 40 años & 40 a 50 años \\
\hline Tratados salario hora & $2.690,62$ & $3.579,48$ & $3.609,64$ \\
Tratados - controles, Unmatched & $-886,95$ & $-1.219,79$ & $-1.365,57$ \\
& $(-8,17)$ & $(-5,18)$ & $(-7,05)$ \\
Tratados - controles, ATT & $-728,63$ & $-1.315,17$ & $-1.285,62$ \\
& $(-5,78)$ & $(-4,82)$ & $(-5,31)$ \\
Variación porcentual & $-27,08 \%$ & $-36,74 \%$ & $-35,62 \%$ \\
Tratados capacitación & 0,24 & 0,29 & 0,3 \\
Tratados - controles, Unmatched & 0,12 & 0,12 & $-0,14$ \\
& $-6,15$ & $-5,9$ & $(-6,04)$ \\
Tratados - controles, ATT & $-0,08$ & $-0,06$ & $-0,05$ \\
& $(-3,67)$ & $(-2,55)$ & $(-1,58)$ \\
\hline
\end{tabular}

Estadístico $\mathrm{T}$ en paréntesis. 
TABLA A.3

TABLA DE AGRUPACION Y COGIDOS DE LAS OCUPACIONES DE LAS ENCUESTAS PIAAC Y CASEN 2015

\begin{tabular}{|c|c|c|c|}
\hline Grupo & $\begin{array}{l}\text { Código } \\
\text { PIAAC }\end{array}$ & $\begin{array}{l}\text { Código } \\
\text { CASEN }\end{array}$ & Ocupación \\
\hline \multirow[t]{4}{*}{ 1. Gerentes } & 11 & 1100 al 1200 & $\begin{array}{l}\text { Ejecutivos, altos funcionarios y } \\
\text { legisladores. }\end{array}$ \\
\hline & 12 & 1200 al 1300 & Gerentes administrativos y comerciales. \\
\hline & 13 & 1300 al 1314 & $\begin{array}{l}\text { Gerentes de producción y servicios } \\
\text { especializados }\end{array}$ \\
\hline & 14 & 1314 al 1400 & $\begin{array}{l}\text { Gerentes de hotelería, venta al por } \\
\text { menor y otro servicio. }\end{array}$ \\
\hline \multirow[t]{6}{*}{ 2. Profesionales } & 21 & 2100 al 2200 & $\begin{array}{l}\text { Profesionales de la ciencia y la } \\
\text { ingeniería. }\end{array}$ \\
\hline & 22 & 2200 al 2300 & Profesionales de la salud. \\
\hline & 23 & 2300 al 2400 & Profesionales docentes. \\
\hline & 24 & 2400 al 2420 & $\begin{array}{l}\text { Profesionales en la administración de } \\
\text { empresas y otros. }\end{array}$ \\
\hline & 25 & 2450 al 2460 & $\begin{array}{l}\text { Profesionales de la información y } \\
\text { comunicaciones. }\end{array}$ \\
\hline & 26 & 2420 al 2450 & $\begin{array}{l}\text { Profesionales legales, sociales y } \\
\text { culturales. }\end{array}$ \\
\hline \multirow{5}{*}{$\begin{array}{l}\text { 3. Técnicos y } \\
\text { profesionales } \\
\text { asociados }\end{array}$} & 31 & 3100 al 3200 & $\begin{array}{l}\text { Profesionales Asociados en Ciencia e } \\
\text { Ingeniería. }\end{array}$ \\
\hline & 32 & 3200 al 3300 & Profesionales asociados de la salud. \\
\hline & 33 & 3300 al 3400 & $\begin{array}{l}\text { Profesionales asociados de negocios y } \\
\text { administración. }\end{array}$ \\
\hline & 34 & 3400 al 3500 & $\begin{array}{l}\text { Profesionales legales, sociales, } \\
\text { culturales y afines. }\end{array}$ \\
\hline & 35 & 3131 y 3132 & $\begin{array}{l}\text { Técnicos de información y } \\
\text { comunicaciones. }\end{array}$ \\
\hline \multirow{4}{*}{$\begin{array}{l}\text { 4. Trabajadores de } \\
\text { oficina }\end{array}$} & 41 & 4100 al 4200 & Oficinistas y secretarios. \\
\hline & 42 & 4200 al 4300 & Empleados de servicio al cliente. \\
\hline & 43 & - & $\begin{array}{l}\text { Secretarios de recopilación de } \\
\text { información. }\end{array}$ \\
\hline & 44 & - & Otros trabajadores. \\
\hline
\end{tabular}




\begin{tabular}{|c|c|c|c|}
\hline Grupo & $\begin{array}{l}\text { Código } \\
\text { PIAAC }\end{array}$ & $\begin{array}{l}\text { Código } \\
\text { CASEN }\end{array}$ & Ocupación \\
\hline \multirow[t]{4}{*}{$\begin{array}{l}\text { 5. Trabajadores de } \\
\text { servicio y ventas }\end{array}$} & 51 & $\begin{array}{c}5100 \text { al } 5130 y \\
5170 \text { al } 5200\end{array}$ & Trabajadores de servicios personales. \\
\hline & 52 & 5200 al 5300 & Trabajadores de ventas. \\
\hline & 53 & 5130 al 5150 & Trabajadores de cuidado personal. \\
\hline & 54 & 5150 al 5170 & $\begin{array}{l}\text { Trabajadores de los servicios de } \\
\text { protección. }\end{array}$ \\
\hline \multirow{3}{*}{$\begin{array}{l}\text { 6. Trabajadores } \\
\text { especializados } \\
\text { en agricultura, } \\
\text { silvicultura y pesca }\end{array}$} & 61 & 6100 al 6151 & $\begin{array}{l}\text { Trabajadores especializados en } \\
\text { agricultura, silvicultura y pesca. }\end{array}$ \\
\hline & 62 & 6152 al 6209 & $\begin{array}{l}\text { Trabajadores forestales, pesqueros y } \\
\text { cazadores orientados hacia el mercado }\end{array}$ \\
\hline & 63 & 6210 & $\begin{array}{l}\text { Agricultores de subsistencia, } \\
\text { pescadores, cazadores y recolectores. }\end{array}$ \\
\hline \multirow{5}{*}{$\begin{array}{l}\text { 7. Trabajadores } \\
\text { de oficios y } \\
\text { trabajadores } \\
\text { relacionados }\end{array}$} & 71 & 7100 al 7200 & $\begin{array}{l}\text { Trabajadores de construcciones y } \\
\text { oficios conexos, excepto electricistas. }\end{array}$ \\
\hline & 72 & 7200 al 7240 & $\begin{array}{l}\text { Trabajadores de metales, maquinaria y } \\
\text { oficios relacionados. }\end{array}$ \\
\hline & 73 & 7300 al 7400 & Trabajadores manuales e impresores. \\
\hline & 74 & 7240 al 7300 & $\begin{array}{l}\text { Trabajadores de la industria el eléctrica } \\
\text { y electrónica. }\end{array}$ \\
\hline & 75 & 7400 al 7500 & $\begin{array}{l}\text { Trabajadores de la industria } \\
\text { alimentaria, de la madera, de la } \\
\text { confección y de otras artesanías. }\end{array}$ \\
\hline \multirow{3}{*}{$\begin{array}{l}\text { 8. Operadores de } \\
\text { plantas y máquinas } \\
\text { y ensambladores }\end{array}$} & 81 & 8100 al 8200 & Operadores de máquinas estacionarias. \\
\hline & 82 & 8200 al 8300 & Ensambladores. \\
\hline & 83 & 8300 al 8400 & $\begin{array}{l}\text { Conductores y operadores de } \\
\text { instalaciones móviles. }\end{array}$ \\
\hline \multirow[t]{6}{*}{ 9. Ocupaciones básicas } & 91 & 9100 al 9200 & Limpiadores y ayudantes. \\
\hline & 92 & 9200 al 9300 & $\begin{array}{l}\text { Trabajadores agrícolas, forestales y } \\
\text { pesqueros. }\end{array}$ \\
\hline & 93 & 9300 al 9400 & $\begin{array}{l}\text { Trabajadores en minería, construcción, } \\
\text { fabricación y transporte. }\end{array}$ \\
\hline & 94 & - & Asistentes de preparación de alimentos. \\
\hline & 95 & - & $\begin{array}{l}\text { Trabajadores de las calles y de las } \\
\text { ventas y servicios relacionados. }\end{array}$ \\
\hline & 96 & - & $\begin{array}{l}\text { Rechazo de trabajadores y otros } \\
\text { trabajadores básicos. }\end{array}$ \\
\hline
\end{tabular}

